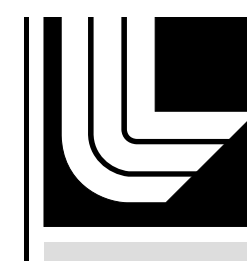

LAW RENCE LIVERMORE NATIO N A L LABORATORY

\title{
Detonation in TATB Hemispheres
}

P. Clark Souers, Bob Druce, Charles Chow, Frank Roeske, Peter Vitello, Constantine Hrousis

March 26, 2004

Propellants, Explosives, Pyrotechnics 
This document was prepared as an account of work sponsored by an agency of the United States Government. Neither the United States Government nor the University of California nor any of their employees, makes any warranty, express or implied, or assumes any legal liability or responsibility for the accuracy, completeness, or usefulness of any information, apparatus, product, or process disclosed, or represents that its use would not infringe privately owned rights. Reference herein to any specific commercial product, process, or service by trade name, trademark, manufacturer, or otherwise, does not necessarily constitute or imply its endorsement, recommendation, or favoring by the United States Government or the University of California. The views and opinions of authors expressed herein do not necessarily state or reflect those of the United States Government or the University of California, and shall not be used for advertising or product endorsement purposes. 


\title{
Detonation in TATB Hemispheres
}

\author{
Bob Druce, P. Clark Souers,* Charles Chow, Frank Roeske, Peter Vitello and Constantine Hrousis \\ Lawrence Livermore National Laboratory, Livermore, CA, USA 94550 \\ *Corresponding author; e-mail: souers1@1lnl.gov
}

\begin{abstract}
Streak camera breakout and Fabry-Perot interferometer data have been taken on the outer surface of 1.80 $\mathrm{g} / \mathrm{cm}^{3}$ TATB hemispherical boosters initiated by slapper detonators at three temperatures. The slapper causes breakout to occur at $54^{\circ}$ at ambient temperatures and $42^{\circ}$ at $-54^{\circ} \mathrm{C}$, where the axis of rotation is $0^{\circ}$. The Fabry velocities may be associated with pressures, and these decrease for large timing delays in breakout seen at the colder temperatures. At room temperature, the Fabry pressures appear constant at all angles. Both fresh and decade-old explosive are tested and no difference is seen. The problem has been modeled with reactive flow. Adjustment of the JWL for temperature makes little difference, but cooling to $-54^{\circ} \mathrm{C}$ decreases the rate constant by $1 / 6^{\text {th }}$. The problem was run both at constant density and with density differences using two different codes. The ambient code results show that a density difference is probably there but it cannot be quantified.
\end{abstract}

Keywords: booster, slapper detonator, Fabry, streak camera, reactive flow

\section{Experimental}

Hemispherical TATB boosters are often used to ignite larger charges of LX-17. In our previous paper,[1] we lit the ambient $1.80 \mathrm{~g} / \mathrm{cc}$ ultrafine TATB with a slapper detonator, as shown in the schematic of Figure 1. The X-axis is the axis of rotation so that there is cylindrical symmetry. The LX-16 detonator drives an aluminum slapper across the air space to hit the TATB in part of section 1 . The detonation spreads into sections 2 and 3 and finally to the quarter-circular edge where measurements are made. The angles from the origin are shown, with $0^{\circ}$ lying on the axis of revolution. As a result of the asymmetric slapper initation, first breakout of the detonation at the outer surface of the $19 \mathrm{~mm}$-radius booster occurred at roughly $60^{\circ}$. Computer modeling of the problem was difficult. The initial radial zoning was abandoned because of the rectangular symmetry of the slapper and reduced connectivity meshing was used, as shown by the sections in Figure 1. Program burn gave a breakout at $80^{\circ}$ and definitely did not work. Reactive flow gave good results but was sensitive to all the input parameters. Possible density variations in the TATB made the problem even more difficult. Better data and analysis is offered here.

The geometry of Figure 1 was again used. The slapper detonator and its effect on TATB have previously been described.[2] The measured times are referenced to the bridge-wire burst that initiates the LX-16. Five curved disks of aluminum foil and Lucite of $8 \mathrm{~mm}$ diameter were placed so that a five-beam Fabry-Perot interferometer (Fabry) could measure the foil velocity at 3, 30, 60, 75 and 85 degrees. 
Hemispheres were measured at ambient, $-20^{\circ} \mathrm{C}$ and $-54^{\circ} \mathrm{C}$. Two kinds of TATB were used: "fresh" and 813 years older.

Figure 2 shows measured streak camera data in terms of bridgewire-burst times. As the sample cools, the curves tighten up with the first breakout angles becoming smaller. We have analyzed the data more thoroughly and show the results in Table 1 . The averages at the bottom cover old and new as there is no difference within error. The breakout angle decreases from $54^{\circ} \pm 4$ at ambient temperatures to $42^{\circ} \pm 4$ at $54^{\circ} \mathrm{C}$, which is a definite change of position. The average breakout angle is the same within error at both $20^{\circ}$ and $-54^{\circ} \mathrm{C}$. The time from the first breakout to time of breakout at $0^{\circ}$ on the axis is also given. because the error is only $\pm 0.01 \mu \mathrm{s}$. This time decreases from $0.09 \mu \mathrm{s}$ at ambient to $0.06 \mu \mathrm{s}$ at both cold temperatures. The bridgewire-burst times to first breakout are the same at $3.87,3.82$ and $3.82 \mu$ s, all \pm 0.05 $\mu$ s from ambient to coldest.

For the purposes of modeling, we need the averages of all these runs, and these are listed in Table 2. The three temperatures are shown along with the high and low bounds. These bounds will be used to illustrate the code runs.

The Fabry shows a rapid jump-up to a maximum velocity value, which then decays slowly with a reshock often pushing it up again. The reshocks appear to be caused by reflections from the sides of the small square foil/LiF packages. The maximum value of particle velocity is roughly related to the maximum pressure in the plastic by the equation

$$
P=\rho_{o}\left(C_{O}+S_{1} u_{p}\right) u_{p}
$$

where the density of lucite is $1.182 \mathrm{~g} / \mathrm{cc}, \mathrm{C}_{\mathrm{O}}$ is $2.18 \mathrm{~mm} / \mu \mathrm{s}$ and $\mathrm{S}_{1}=2.088$.

The Fabry maximum values of measured velocity and calculated pressure are listed in Table $\mathbf{3}$. The scatter in the Fabry data can be estimated from four sets of repeated points, where sets are defined by temperature and age. With this limited calibration, we estimate the measured velocity error to be \pm 0.1 $\mathrm{mm} / \mu \mathrm{s}$ or $\pm 1.6 \mathrm{GPa}$.

It is of interest to try to correlate the shape of the breakout time curves with the pressures obtained from the measured Fabry velocities. These are shown in Figure $\mathbf{3}$ at ambient temperatures, where there are only two old runs and and one new one. The new data lies lower, but, using the error bars derived above, the curves must be judged the same. It is not possible to unravel pressure-angle information from ambient data at this time. 
We now expand out to all the data in Figure 4. In each set, we calculate the pressure difference relative to the $60^{\circ}$ point for both the pressure and the breakout time. There is indeed a linear relationship caused by the large angle data at cold temperatures. The width of the line is about $\pm 3 \mathrm{GPa}$ so that the finer relations at small angles cannot be resolved.

Figure 5 shows the results of plotting the ratio of new to old material velocities at each angle. The ambient data is a little low, but this is the result of the single new set. Only at $85^{\circ}$ is there some evidence of possible change. Overall, a decade of age appears not to have affected the TATB properties.

\section{Calculations}

We reran this problem in JWL++ using the reduced connectivity mesh shown as regions in Figure 1. Section 1 is a square grid at 7 zones/mm used to match the slapper. Sections 2 and 3 are semi-radial in nature. Although not shown here accurately, we added the major air gaps around the LX-16 driver and the foil on the front of it so that the initiation system has the most accurate depiction to date. We use the simple reactive flow model, JWL++, inside a 2-dimensional arbitrary Langragian-Eulerian (ALE) hydrocode of the CALE-type.[3] The detonation rate is given by a single rate constant, $\mathrm{G}_{1}$, using

$$
\frac{d F}{d t}=G_{l}(P+Q)^{b_{l}}(1-F) \approx \frac{1}{2} G_{l} P_{c j}^{b_{l}}
$$

where the second term is what the code gets and the third is an analytical approximation. Decreasing the rate constant slows down the detonation velocity and lengthens the reaction zone. This model creates a dead zone along the edges of the explosive, but detonation failure is not included. The model fails occurs at $b_{1}=3$ so that increasing $b_{1}$ increases the potential for failure.[4] However, increasing $b_{1}$ makes the size (diameter) effect curve more concave down, and the data is slightly concave-up. So a $b_{1}$ of either 1 or 2 is usually used. Running near $b_{1}=3$ makes the model unstable.

An important part of our experiment are the cooled samples, and we want to create a JWL equation of state that corrects for contraction and energy change upon becoming colder. For changing the temperature without having a real temperature in a JWL, we use as input the coefficient of volumetric expansion,

$\tilde{\mathrm{V}} \quad$ in $\mathrm{K}^{-1}$, and the heat capacity at constant pressure per unit volume, $\mathrm{C}_{\mathrm{p}}$, both functions of the absolute temperature, T. We have 


$$
\begin{aligned}
& \Delta V / V_{o}(\text { dim ensionless })=10^{-6}\left(\beta_{1}+\beta_{2} T+\beta_{3} T^{2}\right) \\
& C_{p}\left(k J / \mathrm{cm}^{3} \bullet K\right)=10^{-3}\left(C_{p l}+C_{p 2} T\right)
\end{aligned} .
$$

Both are integrated from the reference temperature of $25^{\circ} \mathrm{C}(298.15 \mathrm{~K})$ to give the change of volume and energy between room temperature and $\mathrm{T}$ :

$$
\begin{aligned}
& \Delta v(\text { dim ensionless })=10^{-6}\left(\beta_{1}(T-298.15)+\frac{\beta_{2}}{2}\left(T^{2}-298.15^{2}\right)+\frac{\beta_{3}}{3}\left(T^{3}-298.15^{3}\right)\right) \\
& \Delta E\left(\mathrm{~kJ} / \mathrm{cm}^{3}\right)=10^{-3}\left(C_{p l}(T-298.15)+\frac{C_{p 2}}{2}\left(T^{2}-298.15^{2}\right)\right)
\end{aligned} .
$$

The original room temperature density is converted to the new density by

$$
\rho_{O}(n e w)=\frac{\rho_{O}}{1+\Delta v}
$$

The detonation energies are changed by

$$
E_{d}(\text { new })=\frac{E_{d}(\text { old })+\Delta E}{1+\Delta v}
$$

As a means of estimating how the detonation energies might change, we use this relationship

$$
U_{S}(\text { new }) \approx\left(\frac{E_{O}(\text { new })}{E_{O}(\text { old })}\right)^{1 / 2} U_{S}(\text { old })
$$

where we assume that the full $\mathrm{E}_{\mathrm{o}}$ is dumped into the explosive immediately even though it is not available for external work until the products expand to infinite volume. For TATB, the values for $\beta_{1}$ through $\beta_{3}$ are 551, -3.84 and 0.00993 in dimensionless units.[5] The values of $\mathrm{C}_{\mathrm{p} 1}$ and $\mathrm{C}_{\mathrm{p} 2}$ in 0.529 and 0.0044 $\mathrm{J} / \mathrm{cm}^{3} \cdot \mathrm{K} .[5,6]$ The resulting JWL has a higher energy density because of contraction but energy is lost from detonation to make up in the cooling. In cooling TATB to $-54^{\circ} \mathrm{C}$, the density increases from 1.80 to 1.833 $\mathrm{g} / \mathrm{cc}$, but the detonation energy at $\mathrm{v}=2.2$ changes from 4.44 to $4.45 \mathrm{~kJ} / \mathrm{cc}$ and the detonation velocity from 7.59 to $7.592 \mathrm{~mm} / \mu \mathrm{s}$. 
In Figure 6, we plot the measured data ranges as listed in Table 2. The broad dark gray lines indicate the range at ambient temperatures and the light gray $-54^{\circ} \mathrm{C}$. The curve passing through the ambient range is $b_{1}=2$ with $\mathrm{G}_{1}=0.06\left(\mu \mathrm{s} . \mathrm{GPa}^{2}\right)^{-1}$. There are two $b_{1}=2$ curves passing through the low temperature data. The left one uses the same room temperature JWL as the ambient run. The right one has the temperature-adjusted JWL. There is little change obtained by adjusting the JWL, but both have $\mathrm{G}_{1}$ lowered to $0.05\left(\mu \mathrm{sPa}^{2}\right)^{-1}$ to fit at $-54^{\mathrm{O}} \mathrm{C}$. We thus have evidence that the rate constant decreases with temperature. If we run at room temperature with $b_{1}=1$, which is a reasonable setting, the curve lies too far to the right with a break-out angle of $60-70^{\circ}$. This suggests that we need failure mixed it somehow in this problem and we are getting it here by raising $b_{1}$. We note, however, that the fits are not so good at small angles.

As reported before, the boosters were ram-pressed and X-ray tomography showed a variation of density.[1] The absolute calibration of this effect has not yet been possible, and we overestimated the differences last time. We may roughly align Figure 1 in the model so that section 1 remains at $1.80 \mathrm{~g} / \mathrm{cm}^{3}$, section 2 is higher at $1.825 \mathrm{~g} / \mathrm{cm}^{3}$ and section 3 is lower, at $1.775 \mathrm{~g} / \mathrm{cm}^{3}$. The ambient result for $\mathrm{b}_{1}=2, \mathrm{G}_{1}$ $=0.06\left(\mu \mathrm{s} \cdot \mathrm{GPa}^{2}\right)^{-1}$ is shown in Figure 7. Fitting the large-angle part is easy but the small-angle part changes. This happens because the on-axis section has a lower detonation velocity than expected, so that the breakout along the axis occurs later. The all $-1.80 \mathrm{~g} / \mathrm{cm} 3$ result is too low in this region, as noted before, but the $1.775 / 1.825 \mathrm{~g} / \mathrm{cm}^{3}$ run is too high. It is possible that a split of $1 / 3$ to $1 / 2$ is closer to the right answer.

It seems important to move from two to three dimensions in the modeling, even though resolution is hard to get when adding the third dimension. We also ran the problem using Ignition \& Growth in 3dimensional LSDYNA, which is also an ALE code.[7, 8] Again, we had a $5 \mathrm{~mm}$ center square section at 8 zones/mm, which changed into a graduated mesh beyond. A total of 510870 nodes and 486692 elements were included. A parabolic shaped aluminum flyer moving at $3.5 \mathrm{~mm} / \mu \mathrm{s}$ simulated the detonator. A 1.5 $\mathrm{mm}$ thick lucite shell was placed around the outer edge of the TATB to simulate the measuring apparatus. Ignition \& Growth is a more complicated reactive flow code requiring twice the minimum zoning as $\mathrm{JWL}++$, so that the 8 zones $/ \mathrm{mm}$ are needed. Its rate equation contains the form $\mathrm{F}^{0.667}(1-\mathrm{F}) \mathrm{P}^{2}$ with a fastreaction rate constant of $0.22\left(\mu \mathrm{sPa}^{2}\right)^{-1}$.[9] The results are shown in Figure 8. Again, the small-angle region is raised by the decrease in density in this section. This run suggests that a spread as large as $1.825 / 1.775 \mathrm{~g} / \mathrm{cm}^{3}$ may be correct.

\section{References}


[1] R. Druce, F. Roeske, P. C. Souers, C. Tarver, C. Chow, R. Lee, E. McGuire, G. Overturf and P. Vitello, "Propagation of Axially Symmetric Detonation Waves," Proceedings Twelfth International Detonation Symposium, San Diego, CA, August 11-16, 2002, to be published.

[2] Alan Frank, Henry Chau, Ron Lee, Peter Vitello and P. Clark Souers, "Reaction Zones in Ultrafine TATB “, Propellants, Explosives, Pyrotechnics 2003, 28, 259-364.

[3] P. Clark Souers, Steve Anderson, Estella McGuire and Peter Vitello, "JWL++: A Simple Reactive Flow Code Package for Detonation," Propellants, Explosives, Pyrotechnics 2000, 25, 54-58.

[4] P. C. Souers, R. Garza and P. Vitello, "Ignition \& Growth and JWL++ Detonation Models in Coarse Zones," Propellants, Explosives, Pyrotechnics 2002, 27, 62-71.

[5] Randy Weese, LLNL, unpublished data, private communication, 2003.

[6] Brigitta Dobratz, The Insensitive High Explosive Triaminotrinitrobenzene (TATB): Development and Characterization- 1884 to 1994, Los Alamos National Laboratory report LA-13014-H (August, 1995).

[7] E. L. Lee and C. M. Tarver, Phenomenological Model of Shock Initiation in Heterogeneous Explosives, Phys. Fluids 1980, 23, 2362-2372.

[8] C. M. Tarver, J. O. Hallquist and L. M. Erickson, Modeling of Short Pulse Duration Shock Initiation of Solid Explosives, Proceedings Eighth Symposium (International) on Detonation, Albuquerque, NM, July 15-19, 1985, pp. 951-961.

[9] Craig Tarver, private communication, 2003.

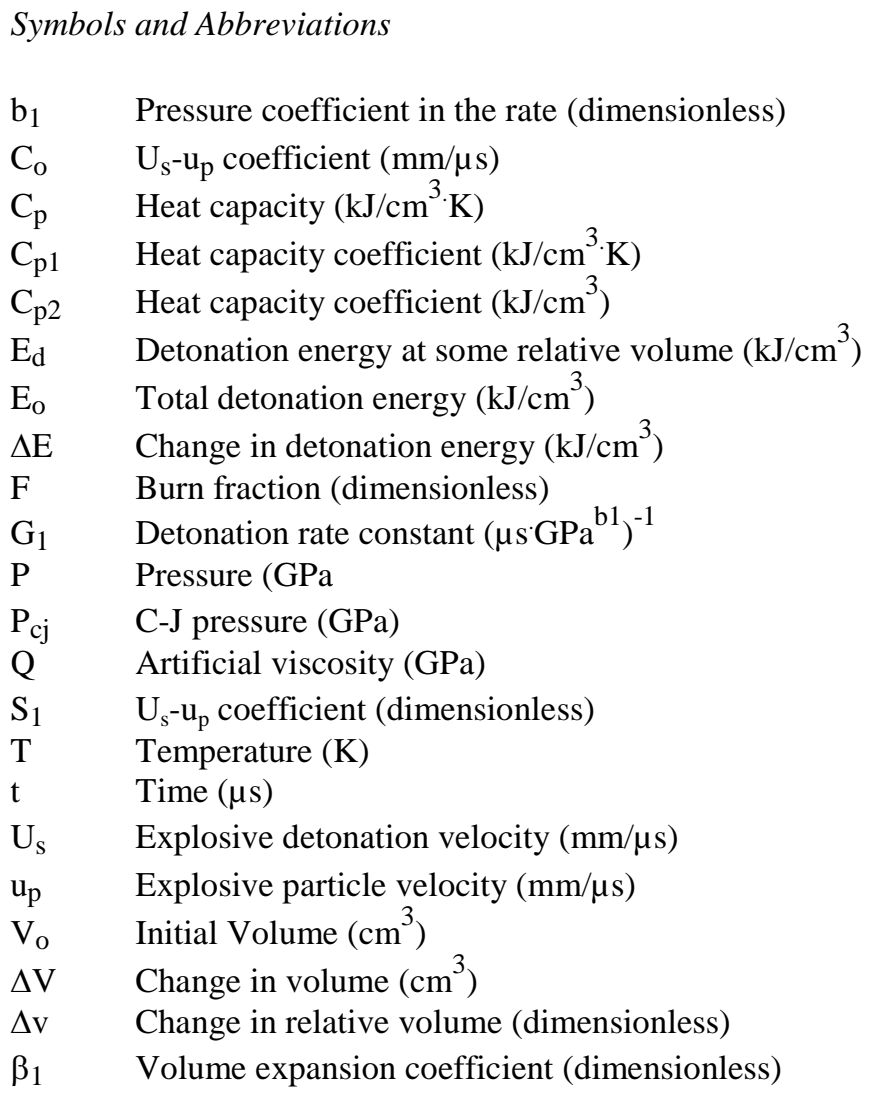


$\beta_{2} \quad$ Volume expansion coefficient $\left(\mathrm{K}^{-1}\right)$

$\beta_{3} \quad$ Volume expansion coefficient $\left(\mathrm{K}^{-2}\right)$

\section{Acknowledgment}

This work was performed under the auspices of the U.S. Department of Energy by the University of California, Lawrence Livermore National Laboratory under Contract No. W-7405-Eng-48. 
Table 1. Streak camera summary of all shots with the TATB hemispheres. Old and new refers to the age of the TATB.

\begin{tabular}{|c|c|c|c|c|c|}
\hline $\begin{array}{c}\text { Temp. } \\
\left({ }^{\circ} \mathrm{C}\right)\end{array}$ & $\begin{array}{l}\text { Shot } \\
\text { Name }\end{array}$ & $\begin{array}{c}\text { Breakout } \\
\text { Angle } \\
\text { (degrees) }\end{array}$ & $\begin{array}{c}\text { Angle } \\
\text { Error } \\
\text { (degrees) }\end{array}$ & $\begin{array}{c}\text { Time to } \\
0^{\circ} \\
(\mu \mathrm{s})\end{array}$ & $\begin{array}{c}\text { Breakout } \\
\text { Time } \\
(\mu \mathrm{s})\end{array}$ \\
\hline \multirow[t]{2}{*}{ ambient } & $09 / 11 / 02$ & 57 & 7 & 0.06 & 3.790 \\
\hline & new & 56 & 6 & 0.08 & 3.770 \\
\hline \multirow[t]{2}{*}{ ambient } & $1 / 27 / 00$ & 56 & 1 & 0.10 & 3.820 \\
\hline & old & 51 & 3 & 0.10 & 3.820 \\
\hline \multirow[t]{2}{*}{ ambient } & $1 / 28 / 00$ & 52 & 3 & 0.09 & 3.810 \\
\hline & old & 52 & 7 & 0.09 & 3.810 \\
\hline \multirow[t]{2}{*}{ ambient } & $1 / 31 / 00$ & 50 & 5 & 0.11 & 3.790 \\
\hline & old & 53 & 2 & 0.10 & 3.800 \\
\hline \multirow[t]{2}{*}{ ambient } & $2 / 3 / 00$ & 51 & 2 & 0.09 & 3.810 \\
\hline & old & 51 & 5 & 0.08 & 3.820 \\
\hline \multirow{2}{*}{ ambient } & $8 / 23 / 01$ & 57 & 5 & 0.08 & 3.690 \\
\hline & old & 63 & 7 & 0.08 & 3.690 \\
\hline \multirow[t]{2}{*}{-20} & $9 / 16 / 02$ & 50 & 4 & 0.06 & 3.780 \\
\hline & new & 45 & 3 & 0.06 & 3.780 \\
\hline \multirow[t]{2}{*}{-20} & 8/28/01 & 39 & 2 & 0.05 & 3.730 \\
\hline & old & 43 & 3 & 0.06 & 3.720 \\
\hline \multirow[t]{2}{*}{-20} & $9 / 4 / 02$ & 46 & 3 & 0.07 & 3.770 \\
\hline & old & 42 & 3 & 0.06 & 3.780 \\
\hline \multirow[t]{2}{*}{-54} & $4 / 12 / 01$ & 45 & 5 & 0.05 & 3.730 \\
\hline & new & 37 & 4 & 0.05 & 3.730 \\
\hline \multirow[t]{2}{*}{-54} & 9/10/02 & 40 & 3 & 0.07 & 3.790 \\
\hline & new & 42 & 3 & 0.06 & 3.800 \\
\hline \multirow[t]{2}{*}{-54} & $8 / 17 / 01$ & 43 & 4 & 0.06 & 3.720 \\
\hline & old & 40 & 5 & 0.05 & 3.730 \\
\hline \multirow[t]{2}{*}{-54} & 8/31/01 & 42 & 4 & 0.06 & 3.730 \\
\hline & old & 43 & 5 & 0.05 & 3.740 \\
\hline \multirow[t]{2}{*}{-54} & $9 / 17 / 02$ & 42 & 4 & 0.05 & 3.860 \\
\hline & old & 42 & 5 & 0.06 & 3.850 \\
\hline ambient & average & 54 & 4 & 0.09 & 3.785 \\
\hline-20 & average & 44 & 3 & 0.06 & 3.760 \\
\hline-54 & average & 42 & 4 & 0.06 & 3.768 \\
\hline
\end{tabular}

Table 2. Breakout time limits in $\mu$ s for the three temperatures. The high and low bounds are listed.

\begin{tabular}{c|cc|cc|cc}
\hline \multirow{2}{*}{$\begin{array}{c}\text { Angle } \\
\text { (degrees) }\end{array}$} & Ambient & & $-20^{\circ} \mathrm{C}$ & & $-55^{\circ} \mathrm{C}$ & \\
\cline { 2 - 7 } & High & Low & High & Low & High & Low \\
\hline 0 & 0.10 & 0.08 & 0.07 & 0.06 & 0.08 & 0.05 \\
15 & 0.09 & 0.07 & 0.06 & 0.04 & 0.05 & 0.03 \\
30 & 0.05 & 0.03 & 0.03 & 0.02 & 0.02 & 0.00 \\
45 & 0.02 & 0.00 & 0.01 & 0.00 & 0.01 & 0.00 \\
60 & 0.01 & 0.00 & 0.08 & 0.01 & 0.11 & 0.03 \\
75 & 0.09 & 0.05 & 0.23 & 0.12 & 0.39 & 0.20 \\
90 & 0.28 & 0.16 & 0.54 & 0.41 & 0.80 & 0.48
\end{tabular}


Table 3. Summary of Fabry measurements. Old and new refers to the age of the TATB.

\begin{tabular}{|c|c|c|c|c|c|}
\hline \multirow{3}{*}{$\begin{array}{c}\text { Temp. } \\
\left({ }^{\circ} \mathrm{C}\right)\end{array}$} & \multirow{3}{*}{$\begin{array}{l}\text { Shot } \\
\text { Name }\end{array}$} & \multirow{3}{*}{$\begin{array}{c}\text { Angle } \\
\text { (degrees) }\end{array}$} & \multicolumn{2}{|c|}{ Maximum Maximum } & \multirow{3}{*}{$\begin{array}{c}\text { Peak } \\
\text { Times } \\
(\mu s)\end{array}$} \\
\hline & & & Velocity & Pressure & \\
\hline & & & $(\mathrm{mm} / \mu \mathrm{s})$ & $(\mathrm{GPa})$ & \\
\hline \multirow[t]{5}{*}{ ambient } & $09 / 11 / 02$ & 3 & 2.71 & 25.1 & 3.91 \\
\hline & new & 30 & 2.77 & 26.1 & 3.87 \\
\hline & & 60 & 2.69 & 24.8 & 3.78 \\
\hline & & 75 & 2.72 & 25.2 & 3.86 \\
\hline & & 85 & 2.70 & 25.0 & 3.92 \\
\hline \multirow[t]{5}{*}{ ambient } & $1 / 27 / 00$ & 7 & 2.95 & 29.1 & 3.92 \\
\hline & old & 30 & 2.90 & 28.2 & 3.89 \\
\hline & & 60 & 2.77 & 26.0 & 3.84 \\
\hline & & 75 & 2.83 & 27.0 & 3.88 \\
\hline & & 85 & 2.65 & 24.2 & 3.98 \\
\hline \multirow[t]{5}{*}{ ambient } & $1 / 28 / 00$ & 7 & 2.84 & 27.2 & 3.90 \\
\hline & old & 30 & 2.88 & 27.9 & 3.86 \\
\hline & & 60 & 2.85 & 27.4 & 3.82 \\
\hline & & 75 & 2.91 & 28.4 & 3.86 \\
\hline & & 85 & 2.64 & 24.0 & 3.94 \\
\hline \multirow[t]{5}{*}{-20} & $9 / 16 / 02$ & 3 & 2.77 & 26.1 & 3.92 \\
\hline & new & 30 & 2.65 & 24.1 & 3.87 \\
\hline & & 60 & 2.71 & 25.1 & 3.85 \\
\hline & & 75 & 2.27 & 18.6 & 4.05 \\
\hline & & 85 & 2.41 & 20.5 & 4.14 \\
\hline \multirow[t]{2}{*}{-20} & $8 / 28 / 01$ & 3 & 2.71 & 25.1 & 3.83 \\
\hline & old & 30 & 2.70 & 24.9 & 3.79 \\
\hline \multirow[t]{5}{*}{-20} & $9 / 4 / 02$ & 3 & 2.91 & 28.4 & 3.91 \\
\hline & old & 30 & 2.93 & 28.7 & 3.87 \\
\hline & & 60 & 2.60 & 23.4 & 3.89 \\
\hline & & 75 & 2.64 & 24.1 & 4.04 \\
\hline & & 85 & 2.38 & 20.1 & 4.18 \\
\hline \multirow[t]{3}{*}{-54} & $4 / 12 / 02$ & 7 & 2.66 & 24.3 & 3.84 \\
\hline & new & 30 & 2.57 & 22.9 & 3.81 \\
\hline & & 60 & 2.45 & 21.1 & 3.87 \\
\hline \multirow[t]{5}{*}{-54} & $9 / 10 / 02$ & 3 & 2.77 & 26.1 & 3.90 \\
\hline & new & 30 & 2.71 & 25.1 & 3.85 \\
\hline & & 60 & 2.73 & 25.4 & 3.94 \\
\hline & & 75 & 1.46 & 9.0 & 3.93 \\
\hline & & 85 & 1.83 & 13.0 & 4.43 \\
\hline \multirow[t]{5}{*}{-54} & 8/17/01 & 3 & 2.77 & 26.1 & 3.92 \\
\hline & old & 30 & 2.65 & 24.1 & 3.87 \\
\hline & & 60 & 2.71 & 25.1 & 3.85 \\
\hline & & 75 & 2.27 & 18.6 & 4.05 \\
\hline & & 85 & 2.41 & 20.5 & 4.14 \\
\hline \multirow[t]{3}{*}{-54} & $8 / 31 / 101$ & 3 & 2.71 & 25.1 & 3.87 \\
\hline & old & 30 & 2.60 & 23.4 & 3.82 \\
\hline & & 60 & 2.60 & 23.4 & 3.91 \\
\hline \multirow[t]{3}{*}{-54} & $9 / 17 / 02$ & 3 & 2.90 & 28.2 & 3.96 \\
\hline & old & 30 & 2.74 & 25.5 & 3.90 \\
\hline & & 60 & 2.58 & 23.0 & 4.01 \\
\hline
\end{tabular}


4.33

4.54 


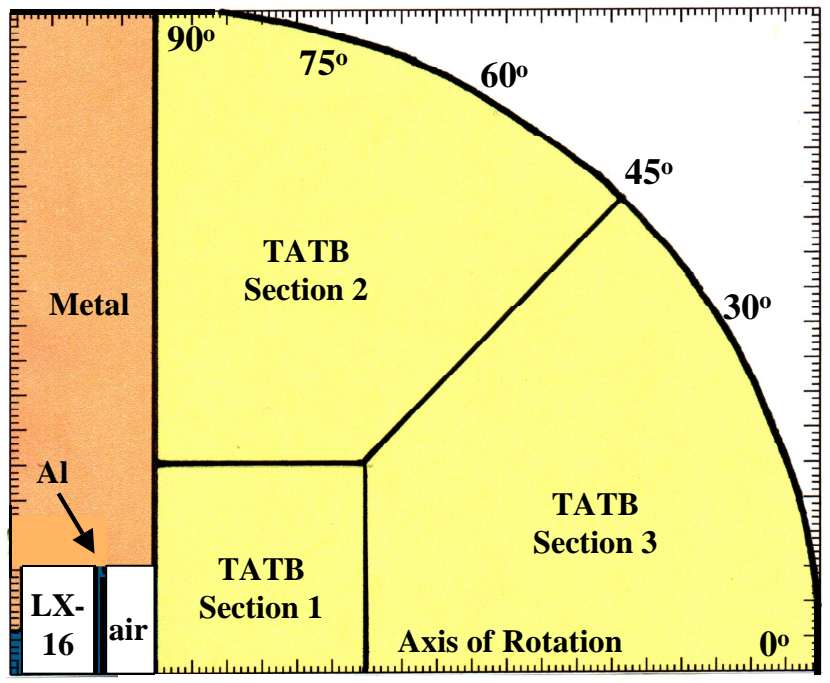

Figure 1. Schematic of the TATB booster, detonator and metal back-up plate. The $\mathrm{X}$-axis is an axis of rotation. The detonation runs from the lower left up and to the right. Measurements are made on the quarter-circle edge at the angles listed in degrees.

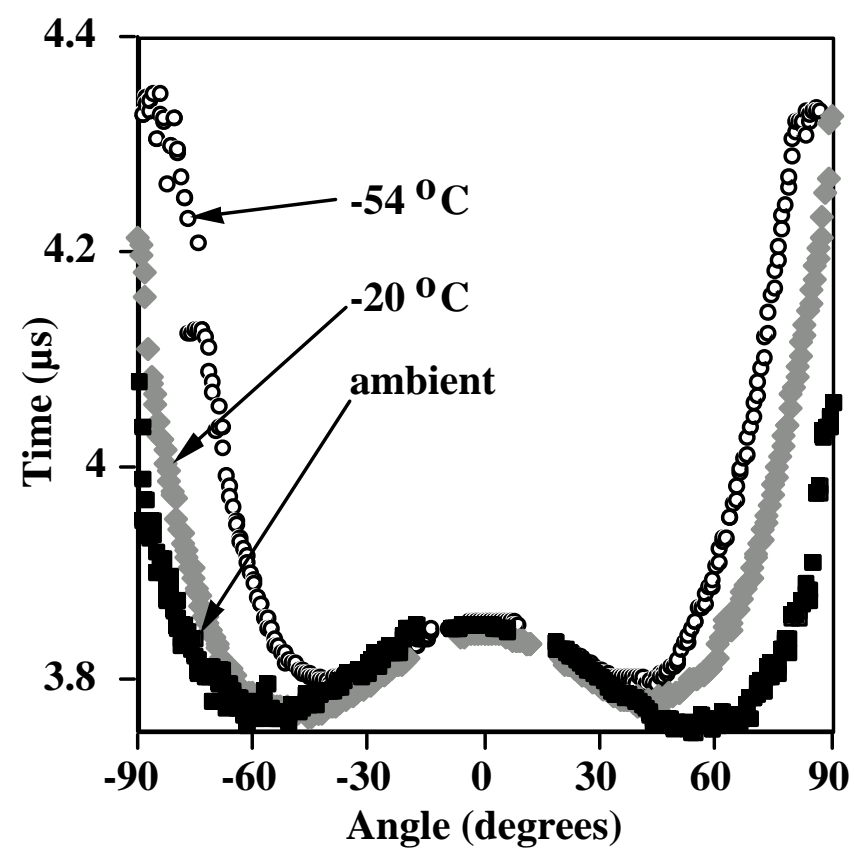

Figure 2. Measured streak camera data showing the first breakout in the vicinity of $60^{\circ}$. As the TATB becomes colder, the curve tightens up, with the first breakout moving to smaller angles. 


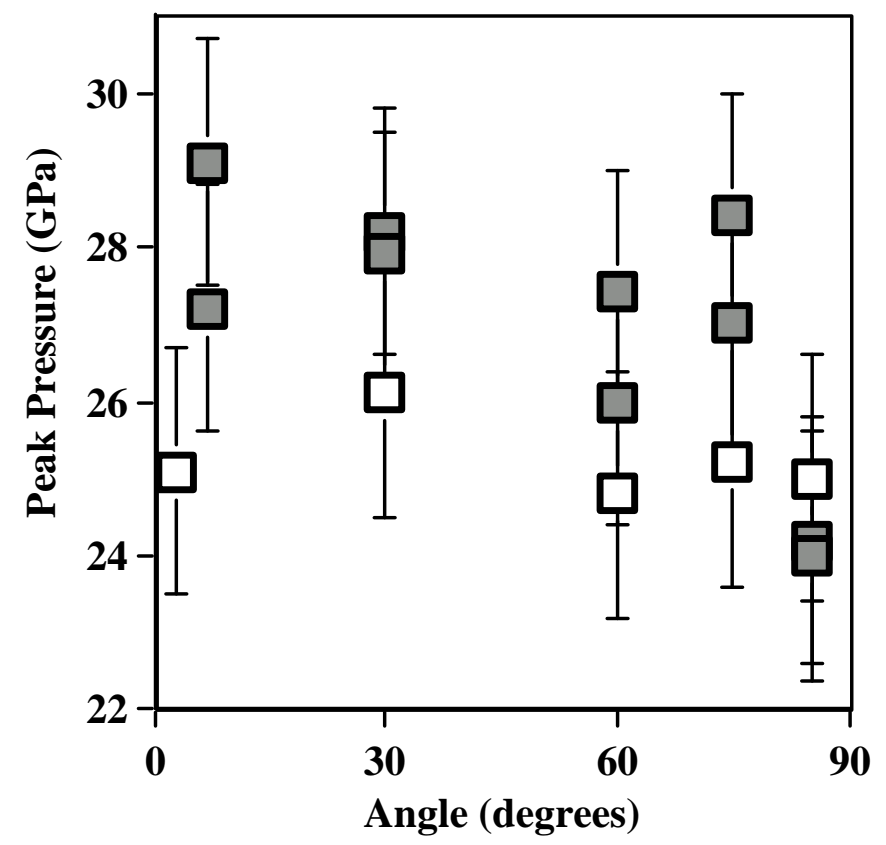

Figure 3. Calculated pressures from Fabry velocity data as a function of angle at ambient temperatures. New points are open and old points are gray.

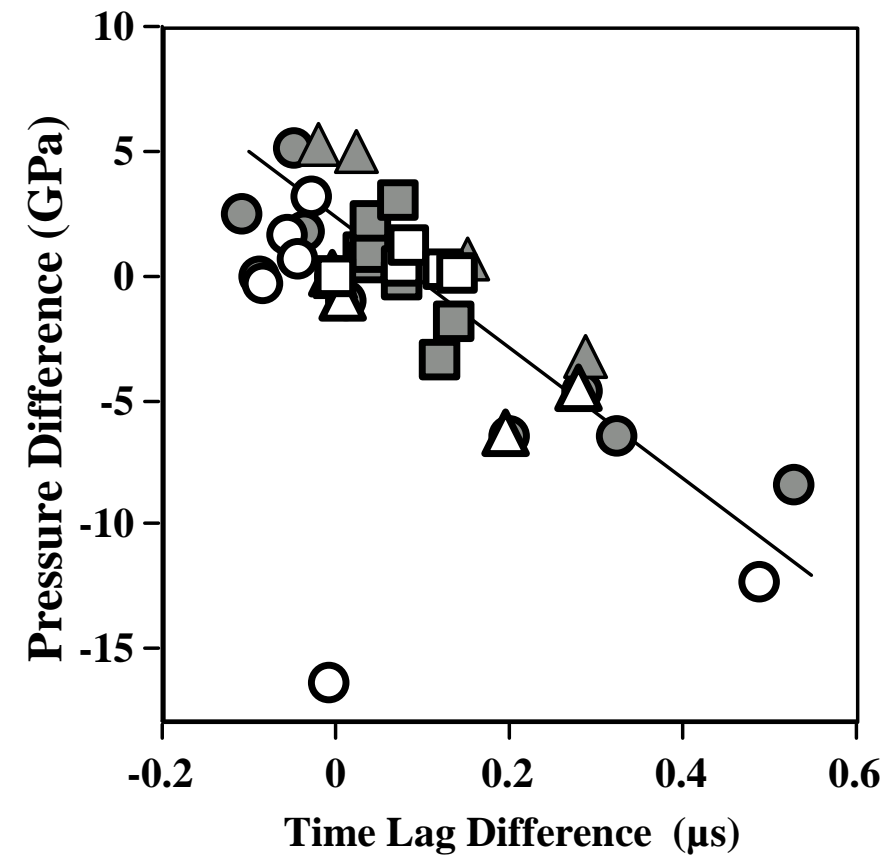

Figure 4. Pressure difference relative to the $60^{\circ}$ pint that set versus the same breakout time difference. There is a linear relationship on a broad scale caused mostly by the large angles at cold temperatures. One point is way out of line. 


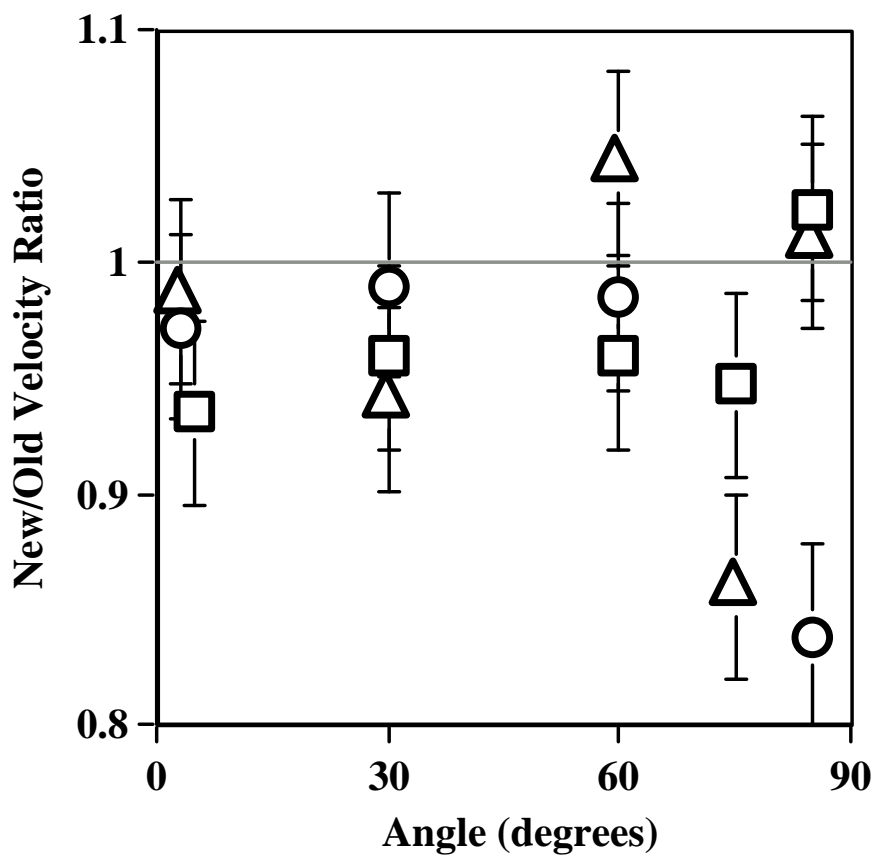

Figure 5. Ratio of measured velocities of new and old explosive as a function of angle. The temperatures are: ambient (square), $-20^{\circ} \mathrm{C}$ (triangle) and $-55^{\circ} \mathrm{C}$ (circle). It is difficult to see a trend in the data.

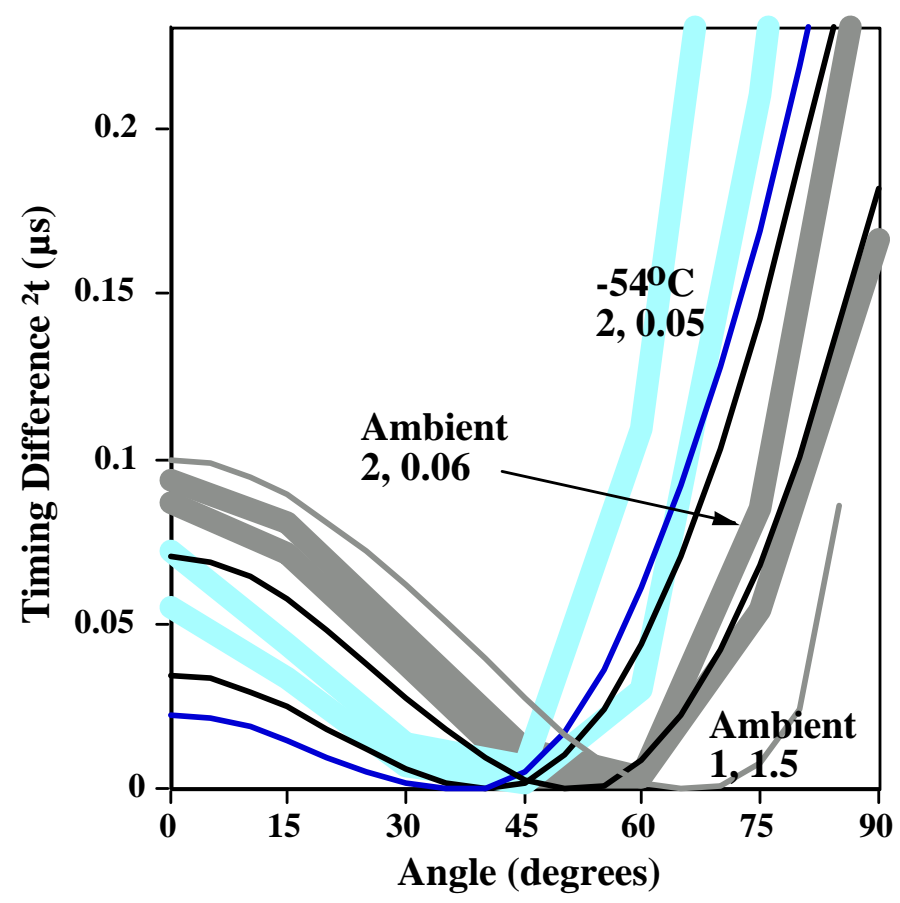

Figure 6. JWL++ runs with streak camera data ranges shown by the broad gray lines for room temperature and the light gray lines for $-54^{\circ} \mathrm{C}$. The code runs for $b_{1}=2$ are close to these ranges, whereas the $b_{1}=1$ run is far off. In order to make the model transition to cold temperature, the rate constant is changed from $0.06\left(\mu \text { s. GPa }{ }^{2}\right)^{-1}$ to 0.05 with cooling. 


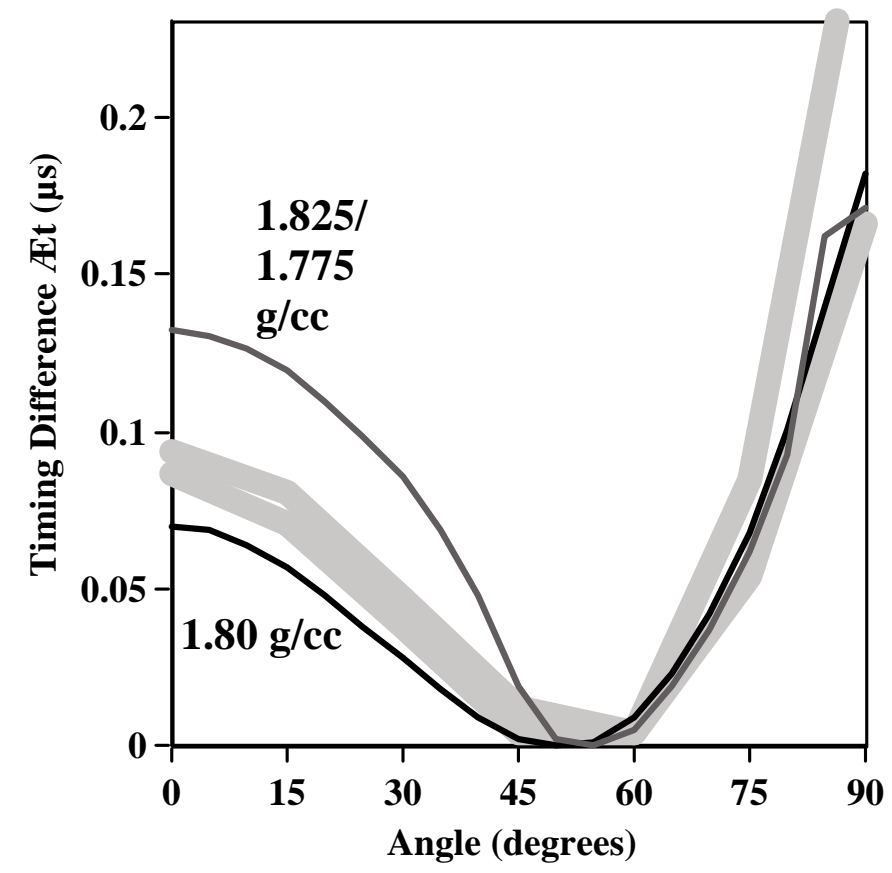

Figure 7. JWL++ ambient $b_{1}=2$ runs at constant and variable density. The actual density spread appears to lie in between.

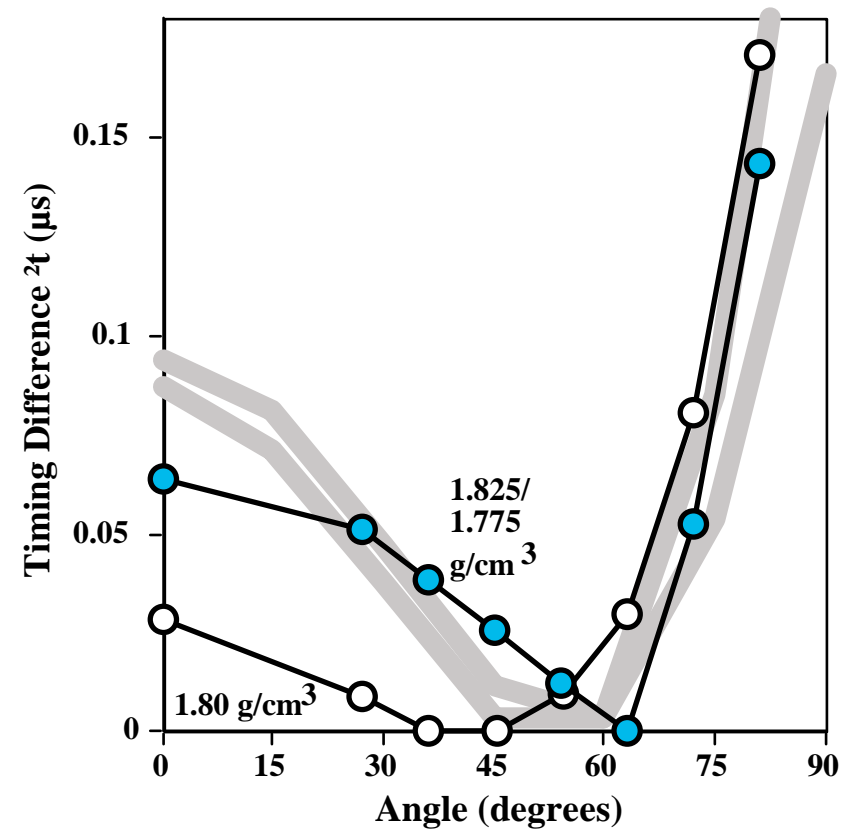

Figure 8. Ambient LSDYNA run in 3-dimensions showing the difference between constant and variable density. 
